\title{
Anterior Cervical Corpectomy and Fusion with excision of recurrent long segmental midline anterior cervical arachnoid cyst
}

\author{
Ashish Jung Thapa $M S^{1}$, Asheesh Tandon $M C h^{2}$, Alok Agrawal $M C h^{3}$ \\ ${ }^{1,2,3}$ Centre for minimally Invasive Brain and Spine Surgery, Aditya Super-specialty Hospital Jabalpur, India
}

\begin{abstract}
Anterior midline cervical arachnoid cysts are very rare, common in the thoracic region. The treatment of midline ventrally lying arachnoid cyst may be challenging via a posterior approach because of a lack of direct visualization of the entire cyst, in particular, its attachment to the cord, complete excision of the cyst wall through a posterior approach is not always possible. Incomplete excision at the first operation and the reaction caused by the epithelial secretion from the marsupialized cyst makes surgery for recurrence very difficult. So, Anterior cervical corpectomy and fusion (ACCF) with cyst excision may be the ideal approach for the anterior midline arachnoid cyst with complete removal and fewer chances of recurrence. Here we report a case of long segmental recurrent midline anterior arachnoid cyst which is completely excised using an anterior cervical corpectomy and fusion and the patient improved drastically neurologically.
\end{abstract}

Key words: Arachnoid cyst, Anterior Cervical Corpectomy, Fusion, Recurrence

\section{Introduction}

\begin{abstract}
A nterior midline cervical arachnoid cysts are very rare in occurrence, common in the thoracic region and posteriorly located. ${ }^{1,2}$ The usual treatment of spinal arachnoid cyst is posterior approach but midline ventral
\end{abstract}

Access this article online
Website: https://www.nepjol.info/index.php/NJN
DOI: https://doi.org/10.3126/njn.v17i2.30168
HOW TO CITE
Thapa AJ, Tandon A, Agrawal A. Anterior Cervical Corpectomy
and Fusion with excision of recurrent long segmental midline
anterior cervical arachnoid cyst: A case report. NJNS.
$2020 ; 17(2): 60-64$

'ORCID id: 0000-0002-1571-604X

${ }^{2}$ ORCID id: 0000-0002-7215-1612

${ }^{3}$ ORCID id: 0000-0003-3733-4162

\section{Address for correspondence:}

Dr. Ashish Jung Thapa

Centre for minimally Invasive Brain and Spine Surgery

Aditya Super-specialty Hospital Jabalpur

Napier Town, Jabalpur 482002, Madhya Pradesh, India

Contact number: +919691808598

E-mail: zenith_horizan@yahoo.com

Copyright (C 2020 Nepalese Society of Neurosurgeons (NESON)

ISSN: 1813-1948 (Print), 1813-1956 (Online) arachnoid cyst may be challenging via a posterior approach because of a lack of direct visualization of the entire cyst, in particular, its attachment to the cord, complete excision of the cyst wall through a posterior approach is not always possible. The complete resection of ventrally located cysts is frequently not amenable without undue manipulation of the cord and spinal cord injury may occur on aggressive removal through a posterior approach. ${ }^{1-3}$ So, anterior cervical corpectomy and fusion (ACCF) with cyst excision may be the ideal approach for the anterior midline cyst with complete removal and fewer chances of recurrence. An arachnoid cyst can be classified into three major categories. Type I are extradural arachnoid cysts without nerve root fibers, Type II are extradural cysts with nerve root fibers, and Type III cysts are intradural cysts. Type 1 cysts can be subcategorized (Type IA) extradural cysts and sacral meningoceles (Type IB). ${ }^{4}$ Here we report a rare case of long segmental Type III cervical cyst located midline anteriorly which had been previously operated twice via posterior approach with incomplete resection leading to recurrence. Long-term follow-up of the incompletely excised cysts and our case can reassure that the ideal treatment of such lesions, incomplete excision at the first operation, and the reaction caused by the epithelial secretion from the marsupialized cyst makes surgery for recurrence very difficult. ${ }^{1-3}$ 


\section{Midline Anterior Cervical Arachnoid Cyst}

\section{Case Report}

A nineteen years old wheelchair bound male, came to our outpatient with chief complaints of quadriparesis, clasp knife rigidity in all the four extremities, pain on lower limbs, tingling and numbness for two months duration. He was previously operated twice within a year interval (posterior cervical laminectomy and cyst excision) at another center. On clinical survey, he was found to have quadriparesis most prominent in the lower extremities with a spastic extension of both lower limbs. His general condition was fair, he had bilateral Hoffman positive, tone- spastic, his muscle power MRC grading was bilateral upper limbs shoulder $3 / 5$, elbow $3 / 5$, wrist $3 / 5$, and fingers $1 / 5$ and for bilateral lower limbs he had a spastic extension. His reflexes were brisk with loss of sensation from $\mathrm{C} 4$ downwards, bowel/bladder- retention, gait- bedridden. His modified Japanese Orthopedic Association scale (mJOA) was 4. MRI showed $\mathrm{C}_{4}-\mathrm{C}_{6}$ anteriorly located recurrent cystic lesion (Figure 1).

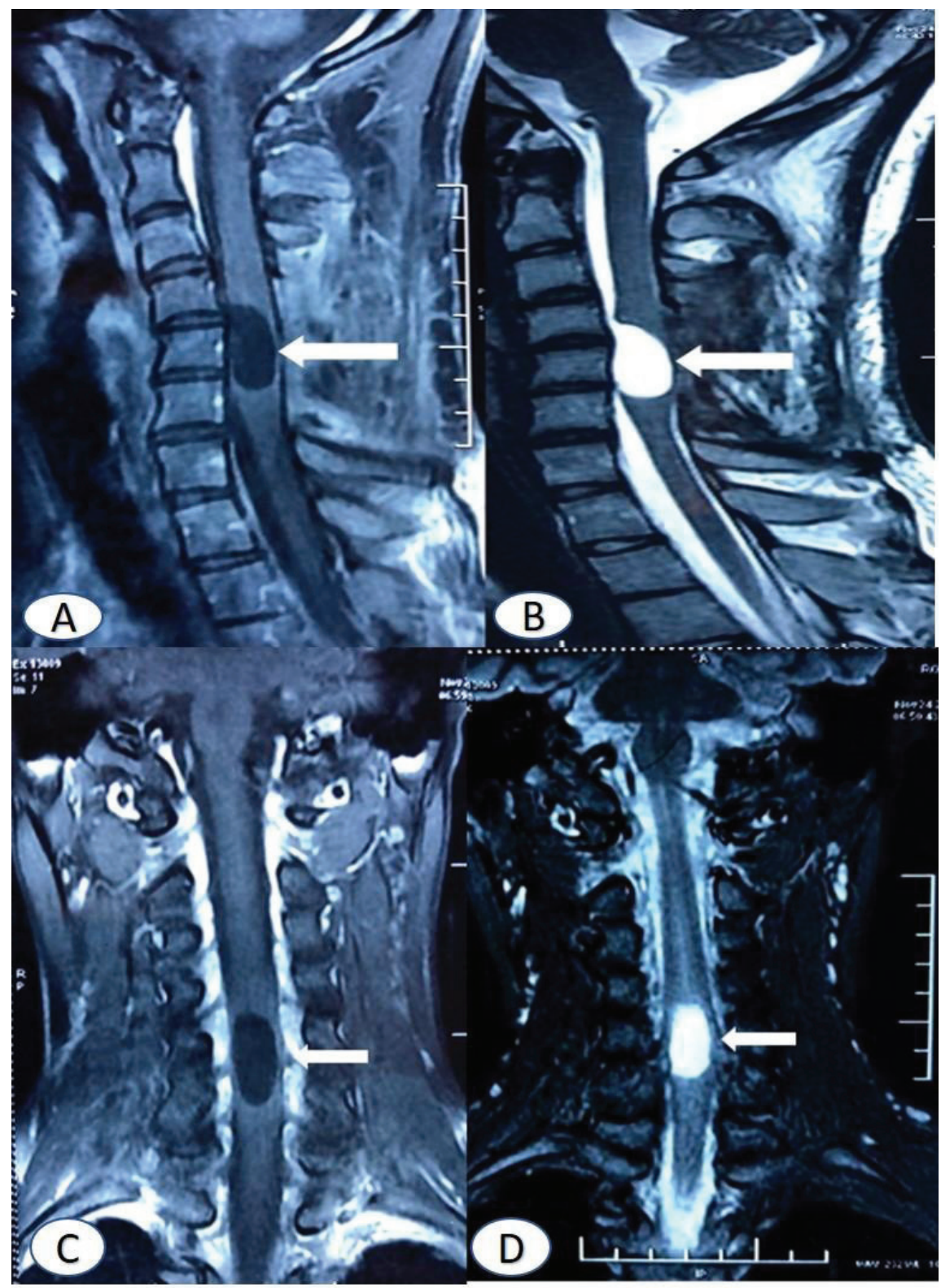

Figure 1: (A) T1W Sagittal image showing cyst (pointed by white arrow). (B) T2W Sagittal image showing cyst (white arrow). (C) TlW Coronal image showing cyst (white arrow). (B) T2W Coronal image showing cyst (white arrow). 


\section{Thapa et al}

The patient was positioned supine with his neck mildly extended, classic Smith- Robin approach was used from the right side to explore the anterior surface of $\mathrm{C}_{4}$, $\mathrm{C}_{5}$ and $\mathrm{C}_{6}$ vertebral bodies. Adequate exposure was made possible by undermining of the platysma, mobilization of the anterior border of the sternomastoid, and division of omohyoid at its tendinous constriction. $\mathrm{The}_{4}-\mathrm{C}_{5}$ and $\mathrm{C}_{5}-$ $\mathrm{C}_{6}$ disc space was confirmed radiologically. The Caspar cervical retractor was hinged underneath the mobilized medial edges of the longus coli muscles bilaterally, thereby safely retracting the trachea and esophagus medially and the carotid sheath and sternomastoid laterally. After $\mathrm{C}_{4}$ $-\mathrm{C}_{5}$ and $\mathrm{C}_{5}-\mathrm{C}_{6}$ discectomies, the anterior surface of the vertebral body of $\mathrm{C}_{5}$ was nibbled off firstly with a bone rongeur then slowly using 1-3 mm Kerrison up cutting rongeur the bone was removed and collected for later use (for filling the titanium cage). Then the remaining bone was denuded and made smooth using high-speed drill and under a microscope, the thinned-down posterior cortical plate at the depth was removed with 1-mm Kerrison rongeur. The intact posterior longitudinal ligament, the dura was very tense and was opened longitudinally, separately, and held back with stay sutures. The thin-walled, tense, pearl white cyst containing clear fluid could be visualized (Figure 2). The cyst was about $4 \mathrm{~mm}$ in diameter and long extending caudally to the mid $\mathrm{C}_{6}$ body intimately adherent to the cord (anterior median sulcus) (Figure 2). The collapsed cyst wall was then slowly removed by fenestration and peeling it off the cord adhesion with sharp microdissection and complete excision of the cyst wall. Watertight dural closure was achieved with a continued stitch (nylon 6-0) and fibrin glue (Figure 2). The corpectomy was extended into the $\mathrm{C}_{4}$ and $\mathrm{C}_{6}$ bodies, retaining their posterior cortices and adjacent cancellous bone and the stop was made short of their upper and lower cortical endplates respectively. At both the cranial and the caudal ends, few millimeter shelves of the anterior cortical plate were undercut. An appropriate length titanium cage was cut and filled with bone pieces (Figure 2) that were inserted into position with mild manual neck traction and fixed with plate and bicortical screws on $\mathrm{C}_{4}$ and $\mathrm{C}_{6}$ bodies then reconfirmed with intraoperative radiography. The omohyoid was repaired and the wound closed over a suction drain.

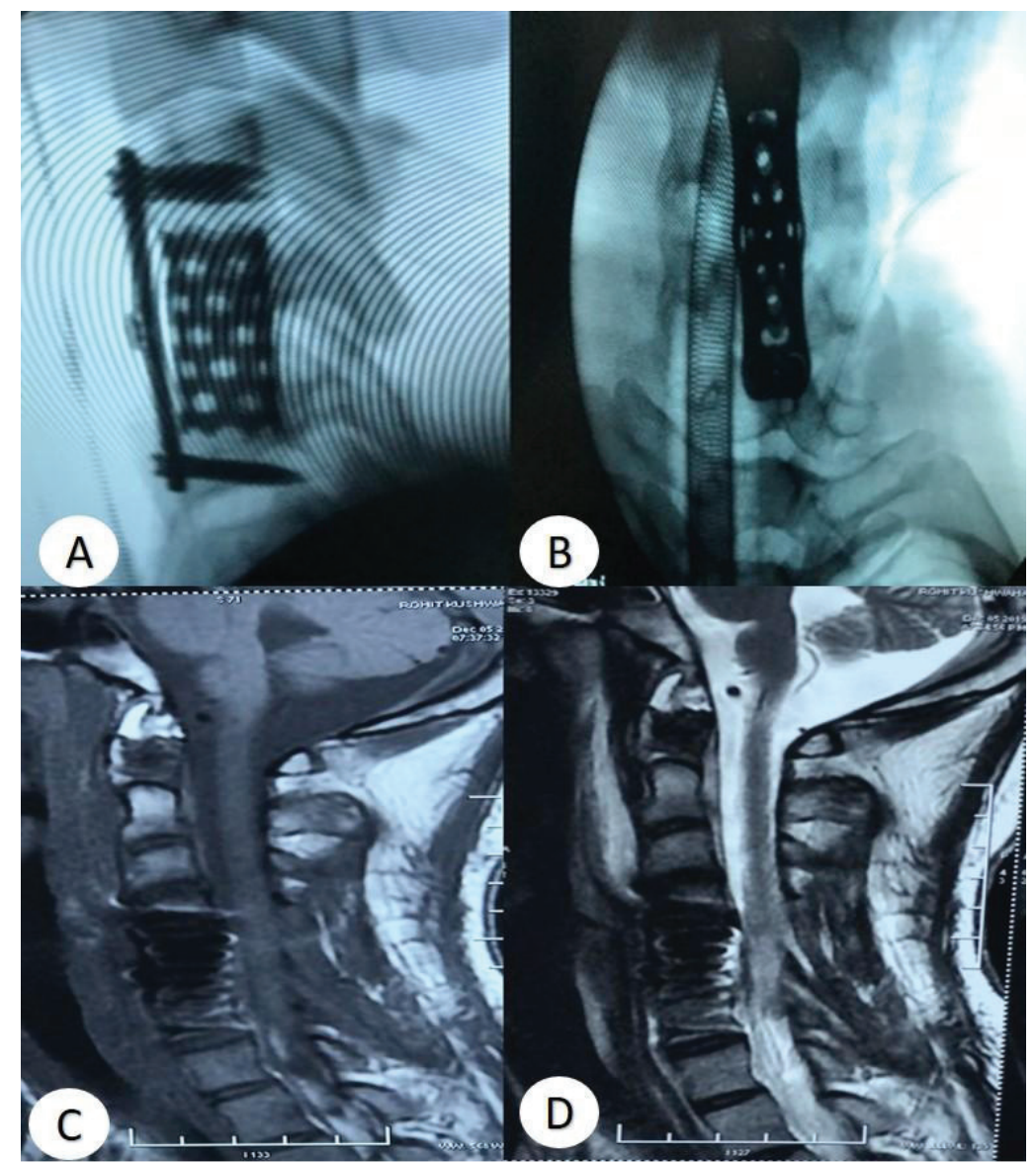

Figure 2: (A) Lateral view C-spine showing CAGE and Plate with cortical screws. (B) AP view C-spine showing CAGE and Plate with cortical screws. (C) Post-operative T1W Sagittal Image with no residual cyst. (D) Post-operative T2W Sagittal Image with no residual cyst. 


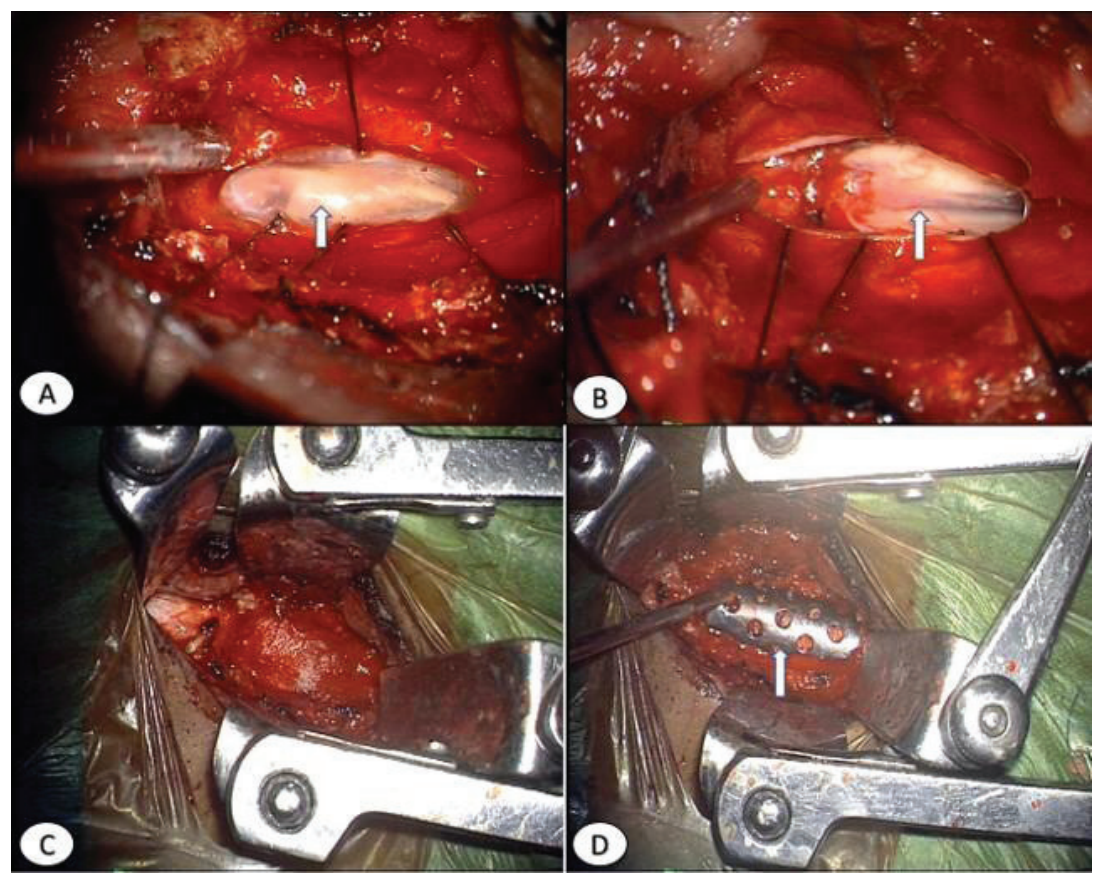

Figure 3: (A) Intraoperative view of the pearl white cyst (pointed by white arrow). (B) Cyst excised and the space along with anterior median fissure (white arrow) shown. (C) Post dural closure gel foam was placed and fibrin glue spread for triple assurance of watertight dural closure. (D) Bone graft packed titanium case in situ (white arrow).

The intraoperative radiology showed the correct placement level and alignment of the cage, plate, and screws (Figure 3). The neck was immobilized in a Philadelphia collar.

Postoperative the patient was shifted to the general ward after anesthesia recovery. He has made a remarkable neurological recovery, he has a good recovery of muscle power in all extremities and his spasticity has been reduced drastically, he was fully mobile with support without neurological deficit. His modified Japanese Orthopedic Association scale (mJOA) was 7 postoperatively. The follow-up MR image showed no residual cyst and satisfactory alignment of the cage. The histopathology report confirmed arachnoid cyst as the diagnosis. 6 months follow up in our outpatient and the patient was able to walk with support with no signs of spasticity. His modified Japanese Orthopedic Association scale (mJOA) was 10 at 6 months follow up.

\section{Discussion}

Anterior midline cervical arachnoid cysts are very rare in occurrence, common in the thoracic region. Surgery is the choice of treatment for arachnoid cysts with gross total resection as the primary goal with total excision being the ideal outcome given the association between partial resection and cyst recurrence. ${ }^{1-3}$ The surgery of the anterior midline cervical intradural arachnoid cyst is a challenge and carries a high risk. Extensive adhesion to cord or other accompanying structural anomalies can make complete resection difficult and hazardous. ${ }^{3,5,6}$ Current literature lacks a consensus on the most appropriate surgical approach among the three prevailing methods: posterior, anterior, and lateral. Each poses its potential benefits and risks associated with the treatment of the spinal arachnoid cyst. Although for arachnoid cysts located ventrally, the posterior technique is the most used surgical approach, and in our case report also both the prior surgeries were done by the posterior approach. The limiting factor of the posterior approach is that the spinal cord will obscure the view of the cyst and dissections of adhesions can prove difficult. ${ }^{5-7}$ An anterior approach is an effective option for the resection of midline ventral arachnoid cysts. Given the goal of total excision, the procedure's plane of access is advantageous in the resection of midline ventrally localized, extramedullary cysts. ${ }^{5-7}$ Furthermore, the anterior approach may reduce the risk for recurrence as it is very low after total excision. In case of insufficient fenestration or aspiration alone, the rate of recurrence is high. ${ }^{2,6,7}$ There is, therefore, enough evidence and our case report itself suggests that the risk of recurrence and partially excised arachnoid cysts, so an attempt should be 
made for their total excision during primary operations, even if this involves a more radical approach.

The recurrence of the arachnoid cyst seems ugly and subsequent surgery gets more difficult so the most appropriate approach should be undertaken during the first attempt. Anterior cervical corpectomy and fusion is the ideal approach for the midline ventral arachnoid cyst providing maximum exposure and fine microdissection plane for the adherent cyst wall to the vital neuronal structures.

\section{Conflict of Interest: None \\ Source(s) of support: None}

\section{References}

1. Muhammedrezai S, Ulu MO, Tanriöver N, Moghaddam AM, Akar Z. Cervical intradural ventral arachnoid cyst resected via anterior corpectomy with reconstruction: a case report. Turk Neurosurg. 2008;18(3):241-4. PMID: 18814111.

2. Rahimizadeh A, Sharifi G. Anterior cervical arachnoid cyst. Asian Spine J. 2013;7(2):119-25. https://doi. org/10.4184/asj.2013.7.2.119

3. Devkota UP, Lam JM, Ng H, Poon WS. An anterior intraduralneurentericcystofthecervicalspine:complete excision through central corpectomy approach-case report. Neurosurgery. 1994;35(6):1150-4. https:// doi.org/10.1227/00006123-199412000-00021. PMID: 7885563.
4. Kong WK, Cho KT, Hong SK. Spinal extradural arachnoid cyst: a case report. Korean J Spine. 2013;10(1):32-4.https://doi.org/10.14245/ kjs.2013.10.1.32

5. Banczerowski P, Lipóth L, Vajda J, Veres R. Surgery of ventral intradural midline cervical spinal pathologies via anterior cervical approach: our experience. Ideggyogy Sz. 2003;56(3-4):115-8. PMID: 12712884.

6. Petridis AK, Doukas A, Barth H, Mehdorn HM. Spinal cord compression caused by idiopathic intradural arachnoid cysts of the spine: review of the literature and illustrated case. Eur Spine J. 2010;19 Suppl 2(Suppl 2): S124-9. https://doi.org/10.1007/ s00586-009-1156-9.

7. Quinn JC, Kiely PD, Lebl DR, Hughes AP. Anterior surgical treatment of cervical spondylotic myelopathy: review article. HSS J. 2015;11(1):15-25. https://doi. org/10.1007/s11420-014-9408-6.

8. Wen Z, Lu T, Wang Y, Liang H, Gao Z, He X. Anterior Cervical Corpectomy and Fusion and Anterior Cervical Discectomy and Fusion Using Titanium Mesh Cages for Treatment of Degenerative Cervical Pathologies: A Literature Review. Med Sci Monit. 2018; 24:6398-404. https://doi.org/10.12659/ MSM.910269.

9. Sklar E, Quencer RM, Green BA, Montalvo BM, Post MJ. Acquired spinal subarachnoid cysts: evaluation with MR, CT myelography, and intraoperative sonography. AJNR Am J Neuroradiol. 1989;10(5):1097-104. PMID: 2505526. 